University of Nebraska - Lincoln

DigitalCommons@University of Nebraska - Lincoln

$8-2000$

\title{
Prostate Cancer Detection, Characterization, And Clinical Outcomes In Men Aged 70 Years And Older Referred For Transrectal Ultrasound And Prostate Biopsies
}

\author{
Jeffrey C. Sung
}

Palo Alto Veterans Affairs Health Care System

John N. Kabalin

University of Nebraska College of Medicine

Martha K. Terris

Palo Alto Veterans Affairs Medical Center

Follow this and additional works at: https://digitalcommons.unl.edu/veterans

Sung, Jeffrey C.; Kabalin, John N.; and Terris, Martha K., "Prostate Cancer Detection, Characterization, And Clinical Outcomes In Men Aged 70 Years And Older Referred For Transrectal Ultrasound And Prostate Biopsies" (2000). U.S. Department of Veterans Affairs Staff Publications. 77.

https://digitalcommons.unl.edu/veterans/77

This Article is brought to you for free and open access by the U.S. Department of Veterans Affairs at DigitalCommons@University of Nebraska - Lincoln. It has been accepted for inclusion in U.S. Department of Veterans Affairs Staff Publications by an authorized administrator of DigitalCommons@University of Nebraska - Lincoln. 


\title{
PROSTATE CANCER DETECTION, CHARACTERIZATION, AND CLINICAL OUTCOMES IN MEN AGED 70 YEARS AND OLDER REFERRED FOR TRANSRECTAL ULTRASOUND AND PROSTATE BIOPSIES
}

\author{
JEFFREY C. SUNG, JOHN N. KABALIN, AND MARTHA K. TERRIS
}

\begin{abstract}
Objectives. To evaluate the diagnostic findings and treatment options chosen in men aged 70 years and older referred for prostate biopsy.

Methods. Age, prostate-specific antigen (PSA), biopsy pathology, clinical stage, treatment pursued, and treatment outcome were analyzed in 210 men age 70 years and older referred for transrectal ultrasound and prostate biopsies. All patients were followed for a mean of 46.9 months (range 28 to 63).

Results. Cancer was found in 120 (56.8\%) of the patients. The cancer detection rate was significantly higher $(81.0 \%)$ in patients aged 80 years and older than those younger than 80 years. Cancer patients aged 80 years and older had a higher rate of poorly differentiated cancer (64.7\%) compared with the 70 to 74-year-olds (33.3\%) and 75 to 79-year-olds (32.1\%). The patients aged 80 years and older also had a larger proportion of high-stage cancer. The patients younger than 80 years had a significantly higher incidence of stable/falling PSA with treatment compared with the older patients. Of the 210 patients, 41 (19.4\%) died within 5 years of the diagnostic procedure; 3 died of prostate cancer. The death rate was not significantly different among the three age groups evaluated. None of the patients aged 80 years and older died of prostate cancer.

Conclusions. Patients aged 80 years and older who are diagnosed with prostate cancer are less likely to respond well to treatment and usually die of unrelated causes. Aggressive diagnosis, staging, and treatment in octogenarians should be guided by the patients' symptoms, overall health, and personal preferences. UROLOGY 56: 295-301, 2000. (c) 2000, Elsevier Science Inc.
\end{abstract}

$\mathrm{T}$ he Prostate Patient Outcomes Research Team (PPORT) reported the national Medicare experience with prostate cancer treatment outcomes in 1993, concluding that aggressive treatment of prostate cancer in patients aged 70 years and older was generally harmful. ${ }^{1}$ Subsequent treatment trends have shown a dramatic drop in the number of patients aged 70 years and older who undergo radical surgery. ${ }^{2}$ Even the aggressive evaluation for the presence of prostate cancer in men aged 70

From the Section of Urology, Palo Alto Veterans Affairs Health Care System, Palo Alto, California; Department of Urology, Stanford University Medical Center, Stanford, California; and Section of Urologic Surgery, University of Nebraska College of Medicine, Scottsbluff, Nebraska

Reprint requests: Martha K. Terris, M.D., Section of Urology (112 C), Palo Alto Veterans Affairs Medical Center, 3801 Miranda Avenue, Palo Alto, CA 94304

Submitted: December 20, 1999, accepted (with revisions): March 16, 2000 years and older is discouraged because treatment options are limited. ${ }^{3}$ However, in clinical practice many men in this age group present for evaluation and counseling. We retrospectively reviewed the presentation and clinical outcome in 210 consecutive men aged 70 years and older who were referred by urologists for transrectal ultrasound and ultrasound-guided prostate biopsy in the 3 years following the PPORT recommendations.

\section{MATERIAL AND METHODS}

From March 1, 1994 to February 28, 1997, 210 men aged 70 years and older were referred to the urology clinic of the Veterans Affairs Palo Alto Health Care System for transrectal ultrasound and ultrasound-guided prostate biopsies. The men ranged in age from 70 to 88 years (mean 74 , median 74). In all patients, serum for determination of prostate-specific antigen (PSA) level and digital rectal examination were obtained prior to the procedure.

PSA levels before biopsy ranged from 0.4 to $564 \mathrm{ng} / \mathrm{mL}$ (mean 23.3, median 9.4). Transrectal ultrasound and ultra- 
sound-guided biopsies were performed in all patients by the systematic sextant method previously described. ${ }^{4}$ Additional directed, transition zone, or seminal vesicle biopsies were performed when clinically indicated. ${ }^{5-8}$ The average number of biopsies taken was 8 (range 6 to 13). Biopsy specimens from each of the sites were labeled and submitted separately for histologic analysis. Each specimen was fixed in 10\% formalin, embedded in paraffin, sectioned longitudinally, and stained with hematoxylin and eosin. Each biopsy core was carefully examined microscopically for the presence of cancer. For each patient, the Gleason grade of any cancer identified was noted. Patients with Gleason grade $3+4$ carcinoma or less were considered well differentiated and those with Gleason grade $4+3$ carcinoma or higher were considered poorly differentiated. ${ }^{9}$

Patients found to have prostate cancer underwent complete clinical staging, including uniform use of bone scintigraphy in all cases. Following initiation of their choice of treatment, patients returned for clinic visits with physical examination and PSA level every 3 to 6 months at either the Palo Alto facility or another Veterans Affairs (VA) facility sharing the VISTA (Veteran's Health Information Systems and Technology Architecture, Department of Veterans Affairs, Technical Services) network through which patients could be followed. Progression of disease was considered three serial rising PSA levels after post-treatment nadir. ${ }^{10}$ For patients on expectant management, three serial PSA rises after diagnosis were used. Those patients without prostate cancer were followed with physical examination and PSA level every 6 to 12 months. All patients were followed for a mean of 52.9 months and median of 58 months (range 34 to 69). Date and cause of death were determined according to documentation in the VISTA system.

Patients were divided into three age groups for analysis: (1) 70 to 74 -year-old group $(\mathrm{n}=132)$, (2) 75 to 79 -year-old group $(n=57)$, and (3) 80-year-old and older group $(n=21)$. As shown in Table I, in the 70 to 74-year-old group, the mean age was 72 years, the PSA levels ranged from 0.4 to $564 \mathrm{ng} / \mathrm{mL}$ (median 9.1), and an average of 8 biopsies were performed per patient (range 6 to 13). In the 75 to 79 -year-old group, the mean age was 76 years, the PSA levels ranged from 1.9 to 120 $\mathrm{ng} / \mathrm{mL}$ (median 8.2), and an average of 8 biopsies were performed per patient (range 6 to 12). In the 80-year-old and older group, the mean age was 83 years, the PSA levels ranged from 3.4 to $360 \mathrm{ng} / \mathrm{mL}$ (median 17.7), and an average of 7 biopsies were performed per patient (range 6 to 10).

Tests for correlation were performed with the Spearman's rank correlation; these correlations were tested for statistical significance by the Mann-Whitney $U$ test. Evaluations for statistically significant differences between unpaired groups were performed with the Student's unpaired two-tailed $t$ test.

\section{RESULTS}

In the 210 patients aged 70 years and older referred for transrectal ultrasound and biopsies, cancer was found in 120 (56.8\%). As shown in Table I, the cancer detection rate was significantly higher in the 80-year-old and older age group, with cancer detected in $17(81.0 \%)$ of the 21 patients, compared with the 70 to 74 -year-old group (cancer in 75 of 132 patients or $56.8 \%$ ) and the 75 to 79 -yearold group (cancer in 28 of 57 patients or $49.1 \%$ ).

Table I shows that of the 75 prostate cancer patients aged 70 to 74 years, $50(66.7 \%)$ had welldifferentiated prostate cancer (grade $3+4$ or less) and 25 (33.3\%) had poorly differentiated cancer (grade $4+3$ or higher). Similarly, in the $28 \mathrm{pa-}$ tients aged 75 to 79 years with prostate cancer, 19 (67.9\%) had well-differentiated tumors and 9 (32.1\%) had poorly differentiated tumors. However, there was an inverse distribution of grade in the 17 prostate cancer patients aged 80 years and older compared with the younger age groups, with only $6(35.3 \%)$ having well-differentiated cancers and $11(64.7 \%)$ having poorly differentiated tumors. There was a significant positive correlation between increasing age and increasing grade $(r=$ $0.4, P<0.0005)$.

Of the 210 patients aged 70 years and older referred for transrectal ultrasound and biopsy, 41 (19.4\%) died within the 2 to 5-year follow-up period (Table I); only 3 (1.4\%) died of complications of their prostate cancer. In the 41 patients who died, their death was an average of 25 months after biopsy (range 3 to 50). Of the 91 patients who underwent prostate ultrasound-guided biopsy but were found to have no cancer, 18 (19.8\%) died during the follow-up period. Of the 120 found to have prostate cancer, 23 (19.2\%) died during the follow-up period; 3 (2.5\%) died of prostate cancer. This difference was not statistically significant. In the older, 80 years and older, age group, 6 (28.6\%) of 21 patients died between 6 and 37 months (mean 23.2) after biopsy. In the 75 to 79 -year-old group, 14 (24.6\%) of 57 patients died between 4 and 50 months (mean 27.8) after biopsy. Of the 132 patients in the 70 to 74 -year-old group, 21 (15.9\%) died between 2 and 39 months (mean 23) after biopsy. No significant difference was seen in the death rate or the time passage between the biopsy procedure and death in any of the three age groups when all patients (both those with and without a diagnosis of cancer) are considered. However, when only the patients with cancer are considered, there was a trend toward increasing death rate with increasing age. There was an overall death rate of $16 \%$ and a $1.3 \%$ prostate cancerspecific death rate for the 70 to 74 -year-old cancer patients, $21.4 \%$ overall and $7.1 \%$ prostate cancerspecific death rate for the 75 to 79 -year-old prostate cancer patients, and $29.4 \%$ overall and $0 \%$ prostate cancer-specific death rate for the 80 -yearold and older prostate cancer patients (Table I).

As expected, the cancer detection rate increased with increasing PSA (Table II); the prostate cancerspecific death rates also increased with increasing PSA in patients younger than 80 years of age, but patients aged 80 years and older died of other causes regardless of PSA at presentation. Similarly, the cancer detection rate increased with increasingly suspicious digital rectal examination (Table III); the prostate cancer-specific death rate increased with worsening rectal examination findings in the patients younger than 80 years of age, 


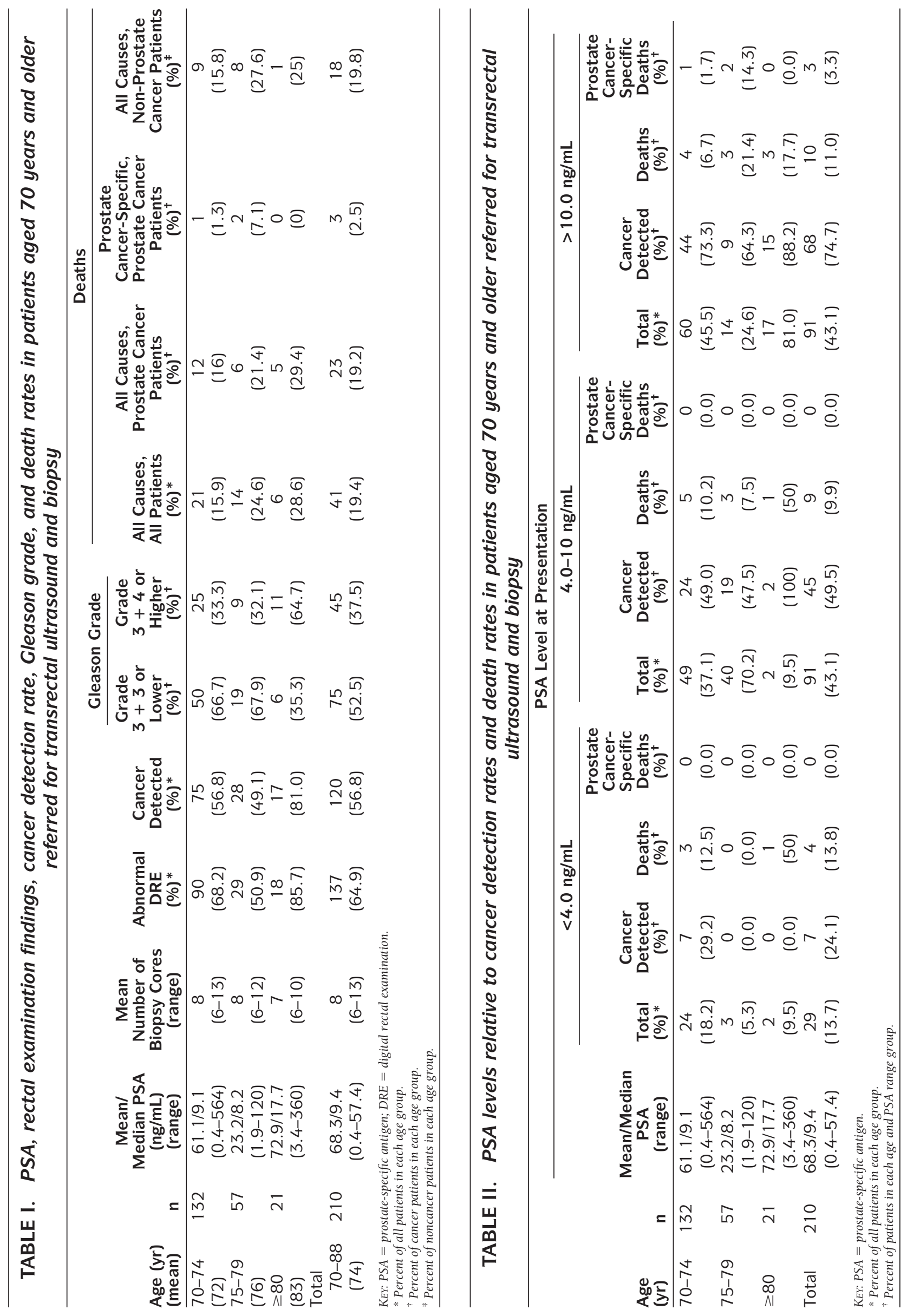


however, patients aged 80 years or older died of noncancer causes regardless of the stage of disease at the time of presentation. Also seen in Table III, $22(18.3 \%)$ of the 120 cancer patients were local Stage T1, 76 (63.3\%) were local Stage T2, and 24 (20.0\%) had local Stage T3 prostate cancer. Further staging evaluation revealed that $10(8.3 \%)$ of the 120 prostate cancer patients had metastatic disease. The proportion of patients with locally advanced or metastatic disease increased with increasing age (Table III). A significant positive correlation existed between increasing age and increasing stage $(r=0.3, P<0.0005)$.

Of the 120 patients aged 70 years and older found to have prostate cancer, 9 (7.5\%) elected to undergo radical prostatectomy (Table IV). One of these 9 patients choosing radical prostatectomy had biochemical failure 32 months following surgery. There were $82(68.3 \%)$ of the 120 prostate cancer patients who chose hormonal therapy, of which $36(43.9 \%)$ of the 82 patients eventually demonstrated progression as measured by a rising PSA during a mean follow-up of 39.5 months. Twenty-two (18.3\%) patients chose expectant management of which 8 (36.4\%) progressed during a mean follow-up of 46.8 months. Seven (5.8\%) chose external beam radiation therapy of which 2 (28.6\%) progressed during a mean follow-up of 35.5 months. No statistically significant difference was seen in the incidence of PSA failure in the patients choosing expectant management between the 70 to 74-year-old group and the 75 to 79 -yearold group, nor was there a difference in the incidence of PSA failure in the patients choosing hormonal therapy between these two age groups. The incidence of biochemical progression during expectant management in the 70 to 74 -year-old group was $30.0 \%$ and in the 75 to 79 -year-old group was $33.3 \%$. In patients undergoing hormonal therapy, the PSA failure rate was $25.5 \%$ in the 70 to 74 -year-old group and $27.8 \%$ in the 75 to 79-year-old group. In contrast, the 80-year-old and older group had a PSA failure rate of $53.8 \%$ for hormonal therapy; this finding was a statistically significant difference from the other two age groups $(P=0.04)$. The 80 -year-old and older patients who chose expectant management also had a substantially higher PSA failure rate of $66.7 \%$, compared with the younger age groups, although this difference did not reach statistical significance.

\section{COMMENT}

We found a higher incidence of prostate cancer, grade, and stage with increasing age as well as a poorer response to therapy. Other authors have observed similar trends. In a large study of nearly 5000 prostate cancer patients, Borek et al. ${ }^{11}$ found that $22.2 \%$ of patients younger than age 60 years had poorly differentiated cancer compared with $32.5 \%$ for patients aged 80 years and older. In a series of 350 radical prostatectomy specimens, Kabalin et al. ${ }^{12}$ found that $75 \%$ of patients older than 70 years had Gleason grade 4 and/or 5 tumor compared with $62 \%$ of those 61 to 70 years old, $54 \%$ in the 51 to 60 -year-old group, and 35\% in those aged 41 to 50 years. In another series based on patients diagnosed as part of a large PSA screening program, Richie et al. ${ }^{13}$ found that the cancer was organ confined in $74 \%$ of patients younger than age 60 years and in $60 \%$ of men older than 70 years of age. Such trends persist even when only the most favorable population is considered. Carter et al., ${ }^{14}$ in a study of 492 men with clinical Stage TIC disease who underwent radical prostatectomy, found that age was a strong predictor of whether or not the cancer was surgically curable on the basis of pathologic findings in the surgical specimens. Similarly, Öbek et al. ${ }^{15}$ have documented a higher biochemical failure rate in $41 \mathrm{pa}-$ tients older than age 70 years who underwent radical prostatectomy compared with 460 patients aged 70 years and younger ( $27 \%$ versus $13 \%$ ), as well as a shorter time until failure (median of 48 months versus median of 60 months). In addition to cancer control concerns, complications of therapy are potentially more dramatic in the older population. Catalona et al. ${ }^{16}$ have shown that the complications of impotence and incontinence are more common in patients aged 70 years and older. LuYao et al. ${ }^{17}$ in a recent review of more than 100,000 patients via Medicare claims found that the 30-day surgical mortality rate following radical prostatectomy for patients between the ages of 65 and 69 years was less than $0.5 \%$, whereas the surgical mortality rate for patients aged 70 years and older approached $1 \%$.

Not all authors agree that older patients will have a less favorable outcome. Corral and Bahnson ${ }^{18}$ reviewed 101 men aged 70 to 79 years with prostate cancer with a mean follow-up of 59 months and compared the $43 \%$ who underwent radical prostatectomy with the $57 \%$ who were treated with hormonal therapy, radiation therapy, or expectant management. In their study, survival for the surgically treated group was significantly better than for the medically treated group. They concluded that men undergoing radical prostatectomy at their institution in the eighth decade of life did not frequently die of intercurrent disease and experienced acceptable morbidity and mortality. Similarly, Huguenin et al. ${ }^{19}$ recently showed no difference in the disease-free survival of men older than 74 years of age treated with radiation therapy for their prostate cancer when compared with matched younger patients. Pow-Sang et al. ${ }^{20}$ in a longitudinal study of 

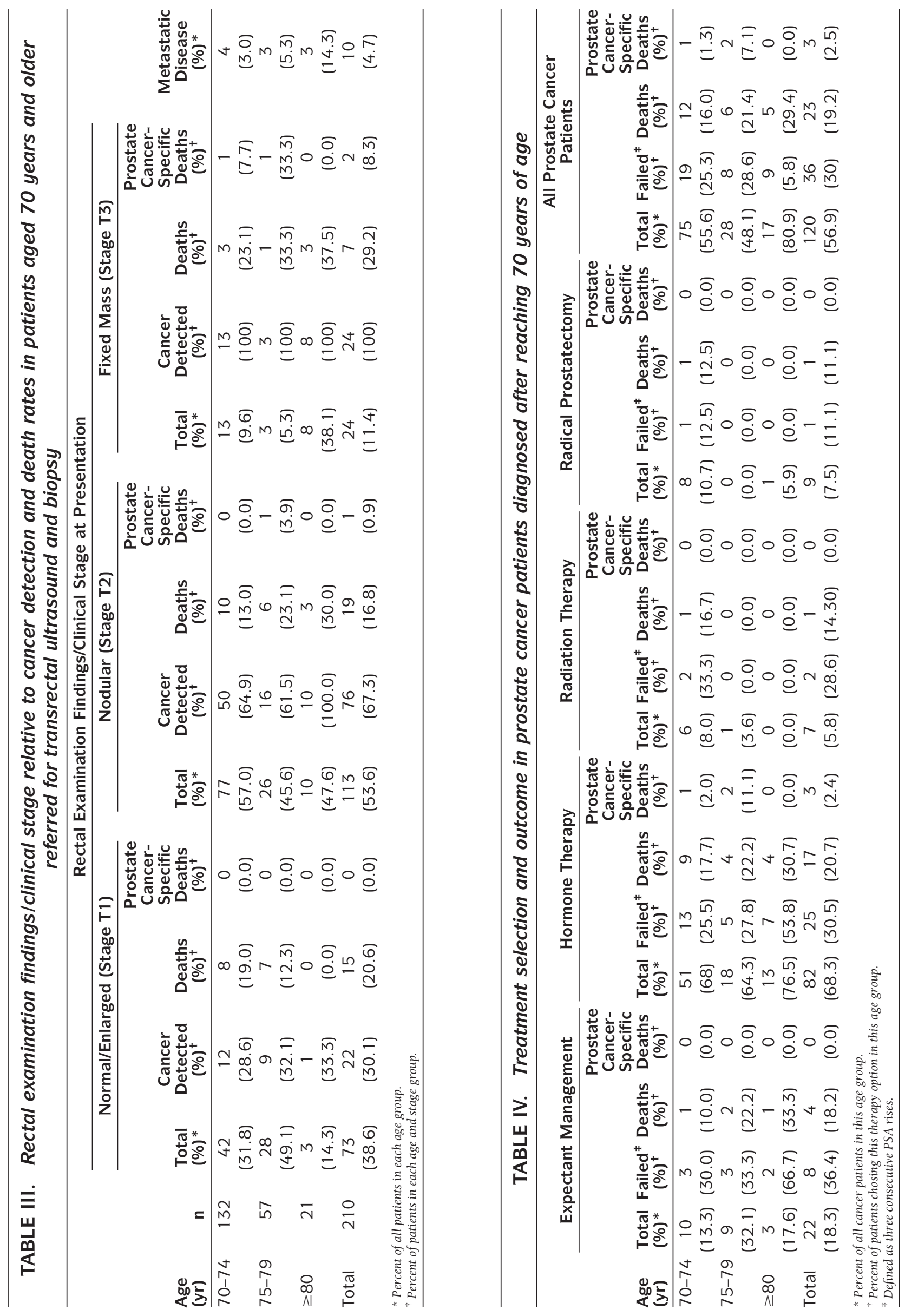
30 high-grade, Stage IV prostate cancer patients aged 80 years or older, found that survival at 3 years was $60 \%$, which was slightly better than patients with similar stage cancer 10 years younger (57.8\%).

The patient population in our study may not represent the more advanced nature of prostate cancer in older patients but rather the hesitance of referring urologists to diagnose low-grade, low-stage prostate cancer in older patients in whom the disease will have no impact on their quantity and quality of life. Many urologists, as well as primary care providers, may appropriately follow elderly, asymptomatic men with expectant management for elevated PSA levels or with digital rectal examination abnormalities, possibly a result of prostate cancer, for which a tissue diagnosis is never made. Neither our study nor a review of the literature clearly defined how aggressive urologists should be for these elderly men. It is generally accepted that screening and aggressive case finding to seek out early, organ-confined disease is contraindicated in those with a life expectation less than 10 years, ${ }^{3}$ but how does the urologist confirm an individual's life expectancy or exclude advanced disease without investigation?

In a study of participants in the Canada Health Survey, Eapen et al. ${ }^{21}$ found that, for prostate cancer patients aged 80 years and older, comorbidity was not a significant predictor of survival. Those researchers admonished against restricting access to PSA screening on the basis of survival probability in elderly patients. Roche et al. ${ }^{22}$ agree that age alone is a poor predictor of survival and an inappropriate factor by which to exclude patients from screening and clinical trials for cancer treatment. They proposed a formal geriatric assessment, including measures of cognitive, functional, and affective status in elderly patients being considered for intervention. Perhaps the most critical of current approaches to prostate cancer in the elderly is a review of several centers by Bennett et al. ${ }^{23}$ that showed that patients aged 75 years and older had significantly less intensive clinical staging evaluations and discussion of treatment options when compared with patients aged 50 to 65 years. Greenfield et al. ${ }^{24}$ have noted similar results in studies of elderly patients with other malignancies and have suggested the presence of widespread age bias in cancer diagnosis, staging, and treatment. Saltzstein et al., 25 in an exhaustive review of more than 14,000 cancer patients older than 90 years of age from the California Cancer Registry, showed that patients older than 90 years of age were diagnosed with cancer at a more advanced stage and received a more abbreviated staging evaluation. Those patients that died, however, usually died of causes other than their cancer. ${ }^{25}$
It is, unfortunately, difficult if not impossible to conduct completely objective discussions of treatment options, particularly with prostate cancer. For example, with asymptomatic, organ-confined prostate cancer, expectant management would be encouraged, and radical prostatectomy would certainly not be presented with enthusiasm as a reasonable option to patients aged 80 years and older, whereas the benefits of surgery and other treatments with curative intent would be strongly recommended to younger patients.

\section{CONCLUSIONS}

In a review of prostate cancer in the elderly by Kirk, ${ }^{3}$ he stated, "The aim always is diagnosis where appropriate, treatment which will be of benefit, and quality rather than length of life." While seemingly simple, following these elusive caveats remains a challenge as the population ages, longevity increases, and prostate cancer therapies evolve.

We discourage screening in asymptomatic elderly and/or debilitated (life expectancy estimated at less than 10 years) patients. Should an asymptomatic man with a modest PSA elevation (less than $20 \mathrm{ng} / \mathrm{mL}$ ) and/or with digital rectal examination abnormality present as a referral for prostate biopsy, we counsel the patient on the low potential of prostate cancer affecting his life expectancy or quality of life as well as the possibility that procedures performed to pursue cancer diagnosis as well as subsequent treatment could significantly affect his quality of life. The final decision, however, remains with the patient.

\section{REFERENCES}

1. Fleming C, Wasson JH, Albertsen PC, et al, for the Prostate Patient Outcomes Research Team: A decision analysis of alternative treatment strategies for clinically localized prostate cancer. JAMA 269: 2650-2658, 1993.

2. Lewis JN, and Rising W: Improving appropriate selection of radical prostatectomy for prostate cancer. Eval Health Prof 21: 429-441, 1998.

3. Kirk D: Prostate cancer in the elderly. Eur J Surg Oncol 24: 379-383, 1998.

4. Hodge KK, McNeal JE, Terris MK, et al: Random systematic versus directed ultrasound guided transrectal core biopsies of the prostate. J Urol 142: 71-75, 1989.

5. Lui PD, Terris MK, McNeal JE, et al: Indications for ultrasound-guided transition zone biopsies in the detection of prostate cancer. J Urol 153: 1000-1003, 1995.

6. Chang JJ, Shinohara K, Bhargava V, et al: Prospective evaluation of lateral biopsies of the peripheral zone for prostate cancer detection. J Urol 160: 2111-2114, 1998.

7. Terris MK, McNeal JE, Freiha FS, et al: Efficacy of transrectal ultrasound-guided seminal vesicle biopsies in the detection of seminal vesicle invasion by prostate cancer. J Urol 149: 1035-1039, 1993.

8. Terris MK, Wallen E, and Stamey TA: Comparison of lateral versus midlobe systematic sextant biopsies in the detection of prostate cancer. Urol Int 59: 239-242, 1997.

9. Stamey TA, McNeal JE, Yemoto CM, et al: Biological 
determinants of cancer progression in men with prostate cancer. JAMA 281: 1395-1400, 1999.

10. Ennis RD, Malysko BK, Heitjan DF, et al: Changes in biochemical disease-free survival rates as a result of adoption of the consensus conference definition in patients with clinically localized prostate cancer treated with external-beam radiotherapy. Int J Radiat Oncol Biol Phys 41: 511-517, 1998.

11. Borek D, Butcher D, and Hassanein K: Relationship of age to histologic grade in prostate cancer. Prostate 16: 305311, 1990.

12. Kabalin JN, McNeal JE, Johnstone IM, et al: Serum prostate-specific antigen and the biologic progression of prostate cancer. Urology 46: 65-70, 1995.

13. Richie JP, Catalona WJ, Ahmann FR, et al: Effect of patient age on early detection of prostate cancer with serum prostate specific antigen and digital rectal examination. Urology 42: 365-374, 1993.

14. Carter HB, Epstein JI, and Partin AW: Influence of age and prostate specific antigen on the chance of curable prostate cancer among men with nonpalpable disease. Urology 53: 126-130, 1999.

15. Öbek C, Sadek S, Lai S, et al: Age as a prognostic factor following radical retropubic prostatectomy. Urology 54: 533$538,1999$.

16. Catalona WJ, Carvalhal GF, Mager DE, et al: Potency, continence and complication rates in 1870 consecutive radical retropubic prostatectomies. J Urol 162: 433-438, 1999.

17. Lu-Yao GL, Albertsen P, Warren J, et al: Effect of age and surgical approach on complications and short-term mor- tality after radical prostatectomy - a population-based study. Urology 54: 301-307, 1999.

18. Corral DA, and Bahnson RR: Survival of men with clinically localized prostate cancer detected in the eighth decade of life. J Urol 151: 1326-1329, 1994.

19. Huguenin PU, Bitterli M, Lutolf UM, et al: Localized prostate cancer in elderly patients: outcome after radiation therapy compared to matched younger patients. Strahlenther Onkol 175: 554-558, 1999.

20. Pow-Sang J, Ramirez G, Benavente V, et al: Prostatic cancer in patients 80 years of age. Prog Clin Biol Res 243: 321-327, 1987.

21. Eapen L, Villeneuve PJ, Levy IG, et al: Comorbid survival among elderly male participants of the Canada Health Survey: relevance to prostate cancer screening and treatment. Chronic Dis Can 19: 84-90, 1998.

22. Roche RJ, Forman WB, and Rhyne RL: Formal geriatric assessment, an imperative for the older person with cancer. Cancer Pract 5: 81-86, 1997.

23. Bennett CL, Greenfield S, Aronow H, et al: Patterns of care related to age of men with prostate cancer. Cancer 67: 2633-2641, 1991.

24. Greenfield S, Blanco DM, Elashoff RM, et al: Patterns of care related to age of breast cancer patients. JAMA 257: $2766-$ 2770, 1987.

25. Saltzstein SL, Behling CA, and Baergen RN: Features of cancer in nonagenarians and centenarians. J Am Geriatr Soc 46: 994-998, 1998. 